Original Research Paper

\title{
The Use of Genetic Optimization for Design of Small Diesel- Battery Submarine
}

\author{
${ }^{1}$ Wisnu Wardhana and ${ }^{2}$ Meitha Soetardjo \\ ${ }^{I}$ Department of Ocean Engineering, Institut Teknologi Sepuluh Nopember, Surabaya 60111, Indonesia \\ ${ }^{2}$ Indonesia Hydrodynamic Laboratory, IHL-BPP Teknologi, Surabaya 60111, Indonesia
}

Article history

Received: 12-11-2016

Revised: 24-11-2016

Accepted: 17-02-2017

Corresponding Author:

Wisnu Wardhana

Department of Ocean

Engineering, Faculty of Marine

Technology, Institut Teknologi

Sepuluh Nopember, Surabaya

60111, Indonesia

Email: wisnuwardhana2@yahoo.com

\begin{abstract}
Design of a Small Diesel-Battery Submarine (SDBS) has been carried out using Multi-Objectives Genetic Algorithm optimization combined with Analytical Hierarchy Process to meet the operation requirements. The objective attributes for this optimization are cost and effectiveness. The product of this optimization is a series of costeffectiveness frontiers in the scattered graph which are used to select alternative designs based on the Indonesian Navy's preference. It is found that the Length of the submarine is $28 \mathrm{~m}$ with Diameter $4 \mathrm{~m}$. The sprint power of 20 knots determines the motor power while the endurance power of 5 knots determines the battery capacity.
\end{abstract}

Keywords: Submarine, Diesel-Battery, Genetic Algorithm, Effectiveness, Cost

\section{Introduction}

Design requirements are based on Indonesia's need for developing capability toward a small submarine design capable of patrolling shallow Indonesian waters and entering the littoral area. The undetected characteristic of submarine, due to its capability to submerge below the sea surface to avoid electromagnetic detection and carry out silent operation, is one of the most important defense tools need to be self-developed (Biantoro, 1998; Jones, 2008).

SDBS mission capability requirements consist of special force delivery, extraction and support, mine laying and countermeasures, defensive ASW and Search and Salvage. The capability of sonar, periscope, radar, optronic, weapon system must all be integrated in a sensor and weapon control system accurately. SDBS must also be equipped with at least two small torpedoes and mines. Navigation and communication equipments must have capability to communicate with surface ships, airplane or other submarines in open or encrypted system. The hull of SDBS must be within the range of: Weight: 100-200 tonnes under snorkeling condition and between 130-300 tonnes during diving, Length: 22-30 m, Breadth or diameter: 4-6 m, Draft: 2-3 m, with single hull of HY60-80 materials. SDBS must have minimum endurance speed of 5 knots with minimum range 300 Nautical Miles for 12-15 days under minimum depth of $150 \mathrm{~m}$. SDBS is operated by 5 officers and 7-9 combat swimmers for special missions (Wardhana, 2015).

\section{Methodology}

The diesel-battery system configuration is as shown in Fig. 1 below where the generator is coupled with the diesel engine while the electric motor is connected via a gear box to propeller. During submerge, the battery is directly connected to the motor. When the submarine is in the snorkeling (surface) condition, the diesel generator set is switched on since the diesel can get air through the snorkel. The generator is used to run the submarine under certain speed while at the same time, part of its power is also used to recharge the battery. In this configuration, there is no direct mechanical connection between diesel engine and the propeller so as to make it easier to arrange them in the engine room.

The optimization method uses the Analytic Hierarchy Process (AHP) combined with MultiAttribute Value Theory (MAVT) to build an Overall Measure of Effectiveness (OMOE) to properly rank and approximately measure the relative mission effectiveness of design alternatives, as used in (Singler, 2004). The AHP hierarchy is then designed according to the mission task. The weight of each factor is then determined from the pairwise comparison through questionaires filled by trained expert opinion of the Indonesian Navy's submarine personnel. This is done especially for determining the relative importance of ASW/ASUW, C4I, ISR, MCM and SPM payload components (Good and Brown, 2006). 


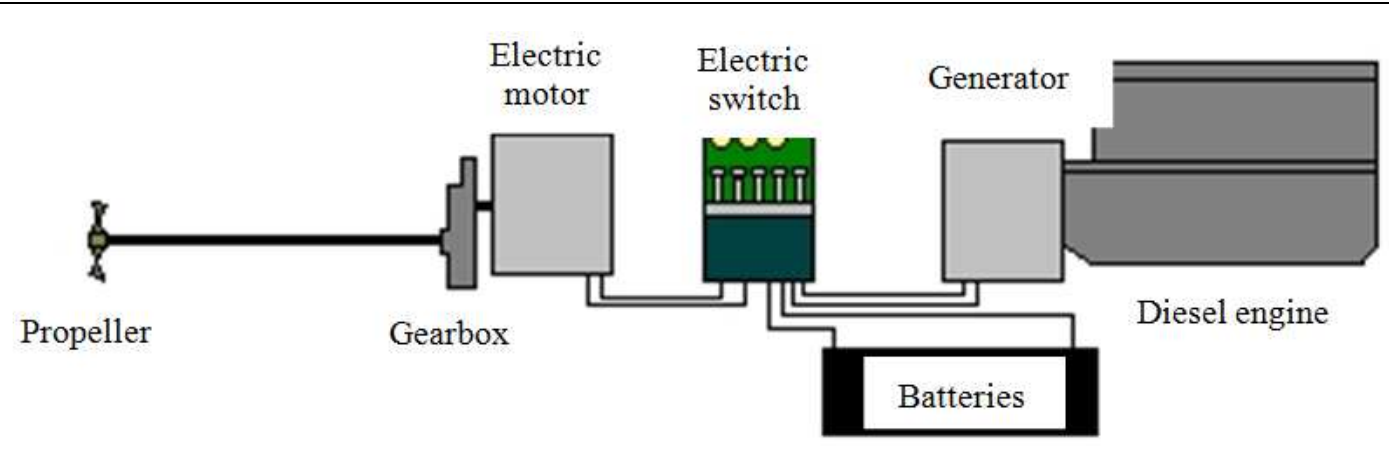

Fig. 1. Diesel-battery system

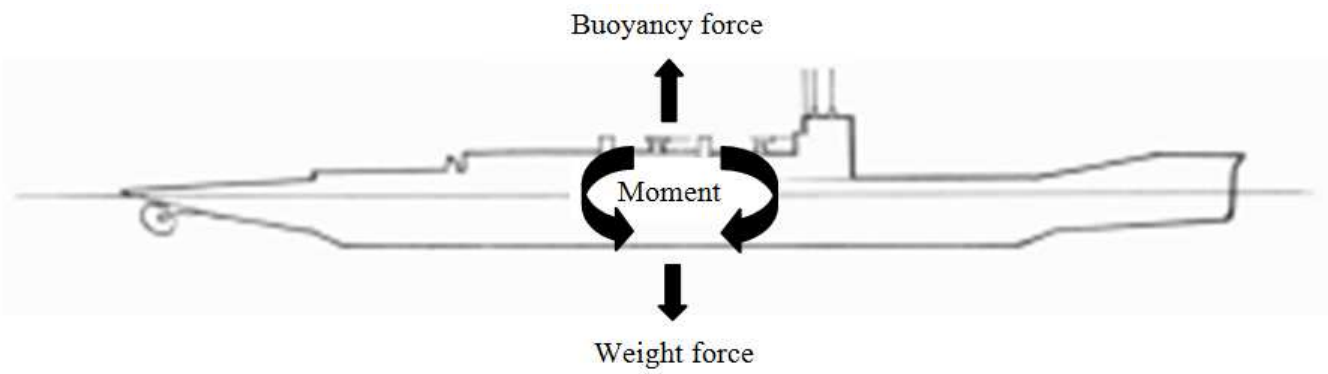

Fig. 2. Force and moment equilibrium of submarine

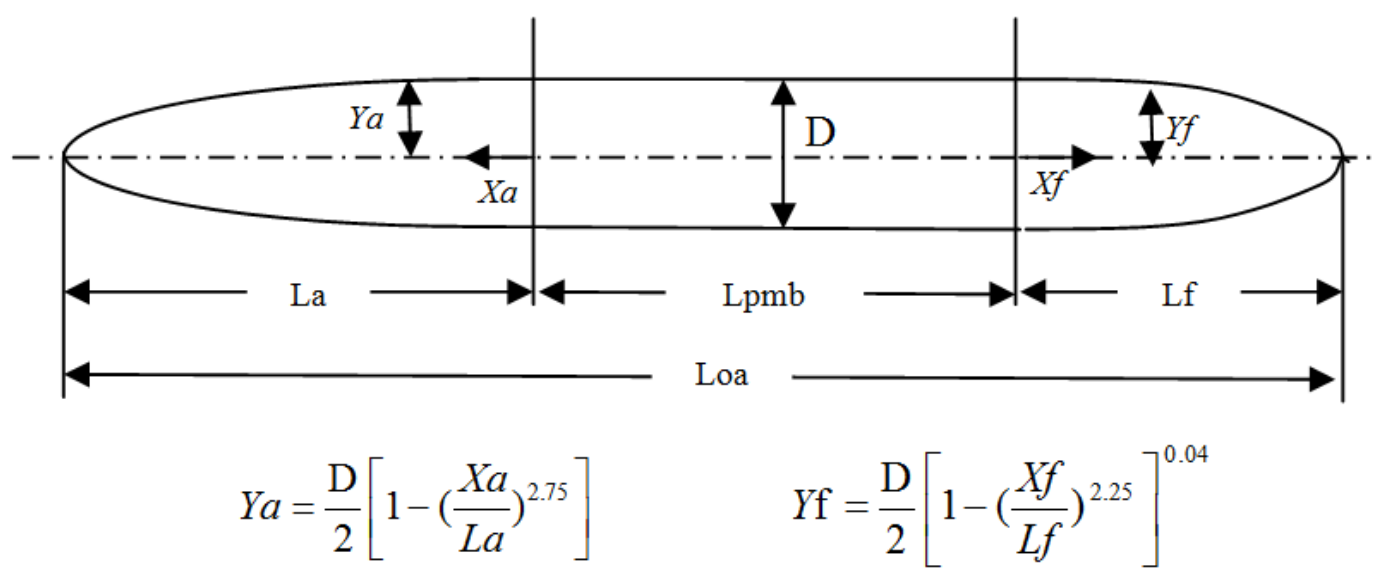

Fig. 3. The idealized hull form

The weight and buoyancy forces and moments of submarine must be always in equilibrium condition, i.e., total Vertical Forces and Moments are equal to zero, $\Sigma \mathrm{F}=0$ and $\Sigma \mathrm{M}=0$, to ensure that the submarine can be hovering in water, allowing some percentage (usually $10-20 \%$ ) of water ballast weight for diving and surfacing purposes, as shown in Fig. 2 above. This implied that the density of submarine must be more or less equal to the density of water.

The weight composes of SWBS standard groups $100,200,300,400,500,600,700,800$ and 900 while the buoyancy force is determined from the volume of submarine.
The idealized hull form used in this calculation is shown in Fig. 3. The hull is divided into 3 parts: La: aft-length, Lpmb: middle body length and Lf: forelength. This form uses circular cross sectional area. The fore and aft parts use equations as shown while the middle part is cylindrical. The length of each part can vary accordingly to meet the needed volume.

The balance between submarine weight in surface condition and ever-buoyant displacement must be achieved in the design process to meet the requirement of $15 \%$ main ballast volume and the appropriate draft to ensure that the total volume is equal to the envelope volume, as shown in Fig. 4 below. 
Wisnu Wardhana and Meitha Soetardjo / American Journal of Engineering and Applied Sciences 2017, 10 (1): 108.113 DOI: 10.3844/ajeassp.2017.108.113

Table 1. Design variables

\begin{tabular}{|c|c|c|c|c|}
\hline $\begin{array}{l}\text { Design } \\
\text { variables }\end{array}$ & Names & Metric & Description & $\begin{array}{l}\text { Trade-off } \\
\text { Range }\end{array}$ \\
\hline DV1 & Lf & Meter & Fore Length & $4-7$ \\
\hline DV2 & Lpmb & Meter & Parallel Middle Body Length & $9-13$ \\
\hline DV3 & $\mathrm{La}$ & Meter & After Part Length & $9-13$ \\
\hline DV4 & B & Meter & Breadth & $4-6$ \\
\hline DV5 & $\mathrm{D}$ & Meter & Depth & $4-6$ \\
\hline DV6 & Cmanning & - & Manning and Automation Reduction Factor & $0.5-1.0$ \\
\hline DV7 & Ts & Days & Mission Length & $12-15$ \\
\hline DV8 & ASW & Alternative & $1=$ Flank array sonar, torpedo room; $2=$ exterior torpedo & $1-2$ \\
\hline DV9 & C4I & Alternative & $1=$ photonic mast $; 2=$ universal mast & $1-2$ \\
\hline DV10 & ISR & Alternative & $1=$ control and process $; 2=\mathrm{NPP}$ imaging process & $1-2$ \\
\hline DV11 & MCM & Alternative & $1=$ forward and side looking sonar; 2 = forward looking sonar & $1-2$ \\
\hline DV12 & SPW & Alternative & $1=7 \operatorname{man} ; 2=8 \operatorname{man} ; 3=9 \operatorname{man}$ & $1-3$ \\
\hline DV13 & Depth & Meter & Operating Depth & $100-150$ \\
\hline DV14 & Ndegaus & Yes/No & Degaussing & $1 / 0$ \\
\hline DV15 & PSYST & Alternative & $\begin{array}{l}\text { Diesel Engine } 1=200 \mathrm{KW}, 2=300 \mathrm{KW} ; 3=400 \mathrm{KW} \\
4=500 \mathrm{KW} ; 5=600 \mathrm{KW} ; 6=700 \mathrm{KW}\end{array}$ & $1-6$ \\
\hline DV16 & BATtyp & Type & $1=$ Lithium ion; 2 = Nickel Cadmium; 3 = Lead acid & $1-3$ \\
\hline DV17 & Ebattery & KWhr & Battery Capacity & $2250-5000$ \\
\hline DV18 & $\mathrm{Ng}$ & Number & Number of Generator & $1-2$ \\
\hline DV19 & Wfuel & Ton & Diesel Fuel Weight & $3-8$ \\
\hline DV20 & Npim & Number & Payload Interface Module & $1-4$ \\
\hline
\end{tabular}

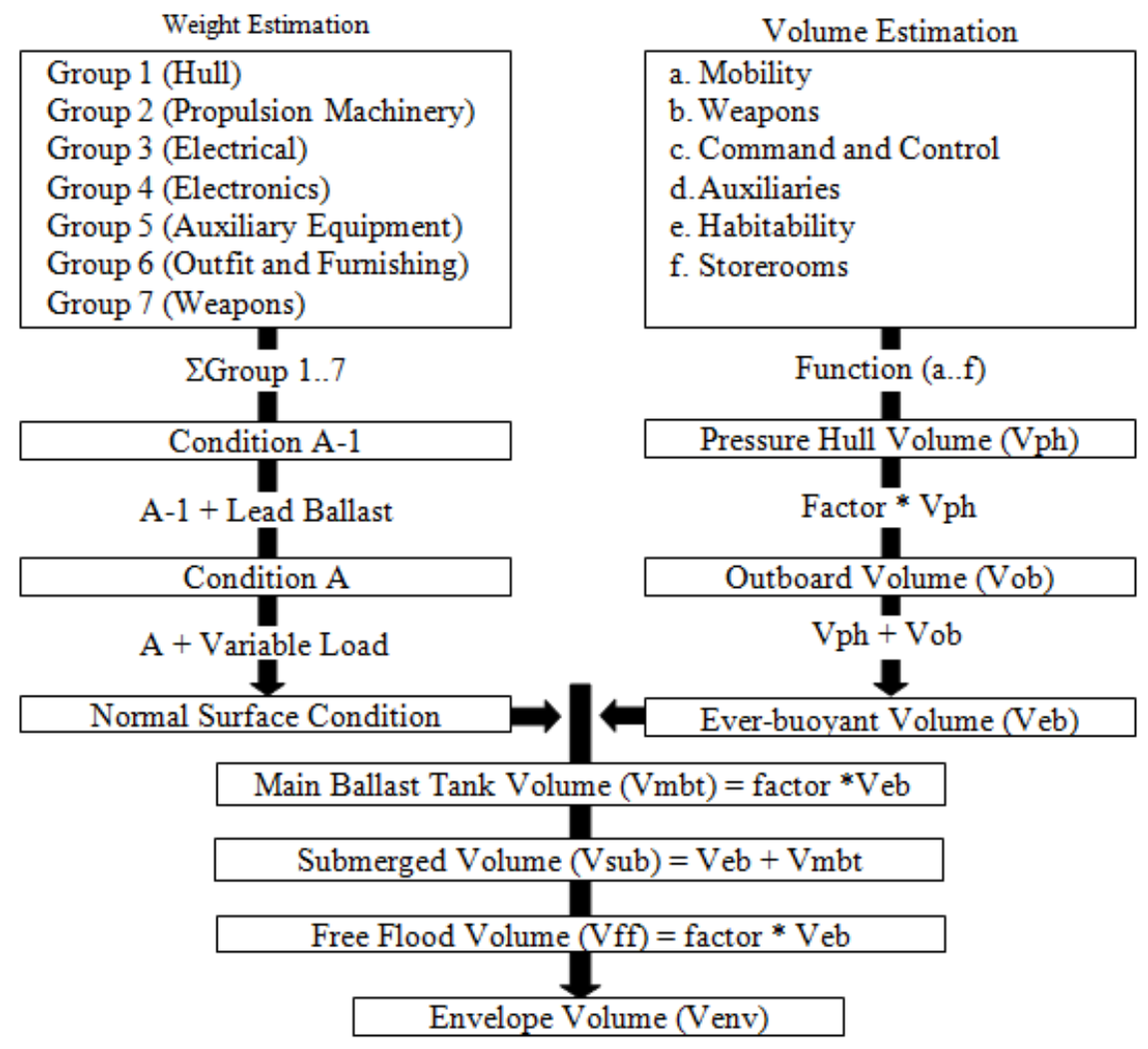

Fig. 4. Balanced volume condition (Singler, 2004)

The stability is checked through the polygon diagram to ensure that SDBS is longitudinally stable. The power of main motor is calculated through the calculation of resistance, EHP, THP, SHP, DHP and BHP using B-series propeller under several series of speed, from endurance speed up to the achieved sprint 
speed. It is shown that motor power is determined from the sprint power while battery capacity is determined from the endurance power. In diving condition, only friction and form drags involved, while in snorkeling (surface) condition, wave making resistance must be added. The electrical demand is calculated based on the electric load analysis to determine the loads for different operating conditions. The diesel power during snorkeling is used for propulsion and for battery charging.

The used 20 design variables (Singler, 2004), each having its lower and upper bound values, are as follows:

\section{Lf, Lpmb, La, B, D, Cmanning, Ts, ASW, C4I, ISR, MCM, SPW, Depth, Ndegaus, PSYST, BATtyp, Ebattery, Ng, Wfuel, Npim,}

The description of those variables and their bound values are as shown in Table 1 above.

\section{Results}

Submarine design calculation is basically a spiral process in nature (Wardhana, 2015). The aspects calculated in the process are: Hull geometry, resistance and power, mechanical and electrical, manning and automation, subdivision, area and volume, machinery arrangement, general arrangement, structure, weight and stability, sea keeping, cost and effectiveness. The optimization process, as shown in Fig 5 above, is done iteratively until feasible condition is achieved, i.e., when the available values of certain parameters are greater than the required ones. Designs fall in feasible region are then collected to get the optimum design of minimum cost.

Objective attributes for this Optimization are cost and Military Effectiveness (OMOE). The product of the optimization should be a series of cost-riskOMOE frontiers (Good and Brown, 2006) which are used to select alternative designs based on the Indonesian Navy's preference, although up to this stage, only the OMOE and cost are considered due to limitation of risk data. In the scatter diagram Fig. 6 below, in which, every design point is optimum at certain OMOE value. The scatter also forms a nondominated frontier, layer of highest OMOE at certain value of cost. As shown in the figure, there is a 'prefer' chromosome from the designer's point of view i.e., the chromosome at the 'kinked' position, where addition of little cost will give significant improvement of OMOE value, as shown by the arrow.

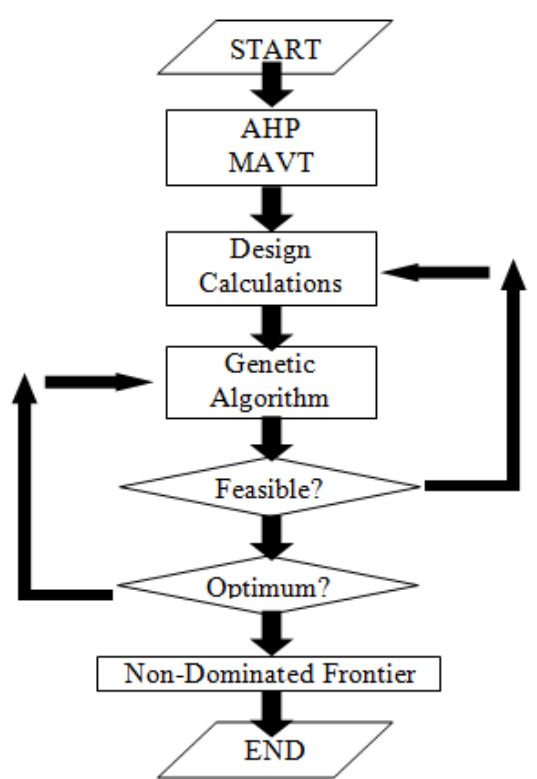

Fig. 5. Optimization process

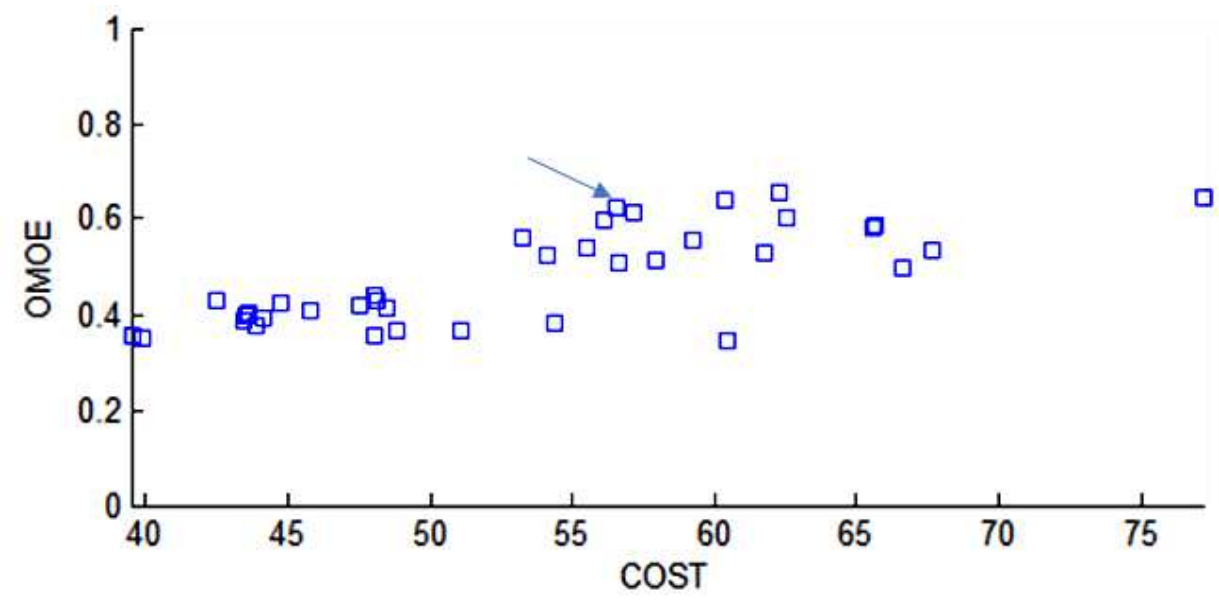

Fig. 6. Propulation of optimum results and the non-dominated frontier 


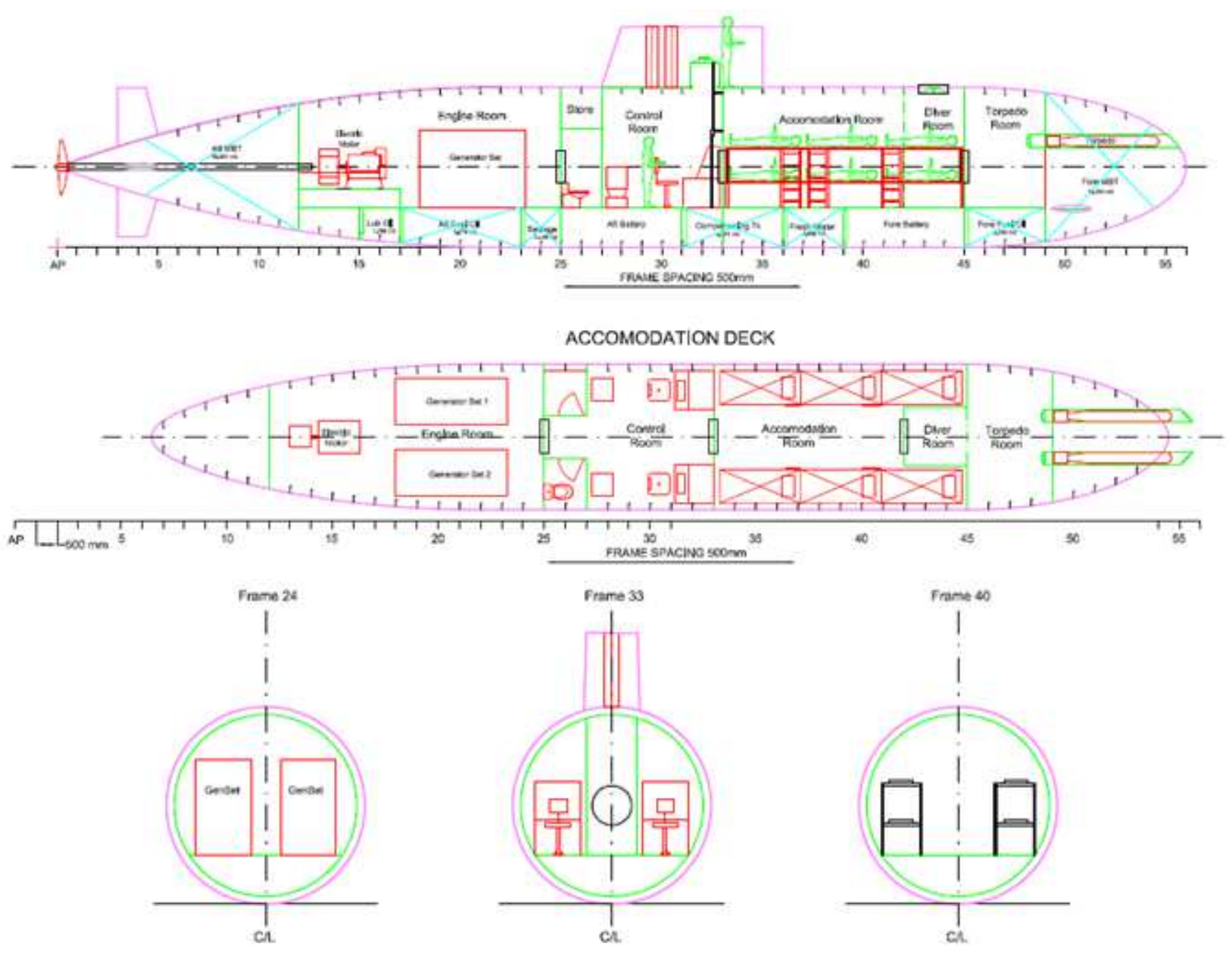

Fig. 7. General arrangement

Parameters involved in the feasibility calculation are: Area, volume and weight, power, endurance speed and range, sprint speed and range and also the stability values etc. These values also reflect the flexibility of the factor could vary within the range. The resulted parameter values of the chosen chromosome are then plotted in the general arrangement, as seen in Fig. 7 above.

Having rounding the values, it is found that the optimum principle dimensions of SDBS are LOA $=28$ meters, Diameter $=4$ meters, endurance speed $=5$ knots and sprint speed around 20 knots.

\section{Conclusion}

Principle dimensions and other important parameters of 'best' SDBS is presented in the exploration concept stage. Concept Development will be continued to include in detail the hull form development, structural finite element analysis, propulsion and power system development and arrangement, general arrangements, machinery arrangements, combat system definition and arrangement, equilibrium polygon analysis, cost and producibility and risk analysis.

\section{Acknowledgement}

This paper is about designing a diesel-battery submarine for Indonesian waters using the method developed by (Good and Brown, 2006) and (Singler, 2008). It is part of the research funded by Ministry of Defense 2015. The gratitude is also given to Diar, Ede and Frea for their patient and help during the research.

\section{Author's Contributions}

All authors equally contributed in this work.

\section{Ethics}

Any ethical issues that may arise after the publication of this manuscript are under the author responsibility. 


\section{References}

Biantoro, D., 1998. Some aspects of in diesel-submarine technology. Indonesian Navy Magazine, Jakarta.

Good, N. and A. Brown, 2006. Multi objective concept design of ALDV. ASNE.

Jones, B., 2008. Technological aspects of submarine. Journal Underwater Technology Canberra.
Singler, K., 2004. Littoral warfare submarine. Aerospace and Ocean Engineering.

Wardhana, W., 2015. Numerical and experimental assessments of midget for military application in Indonesia. Riset Insentif, Ristek, Jakarta, 2007-2015. 